\title{
Hybrid Renewable Energy System with Storage for Electrification - Case Study of Remote Northern Community in Canada
}

\author{
Michela Longo*, Wahiba Yaïci**+, Federica Foiadelli* \\ *Department of Energy, Politecnico di Milano, 34-20156 Milan, Italy \\ **CanmetENERGY Research Centre, Natural Resources Canada, 1 Haanel Drive, Ottawa (Ontario) K1A 1M, Canada \\ (michela.longo@polimi.it, wahiba.yaici@canada.ca, federica.foiadelli@polimi.it) \\ ^Corresponding Author; Wahiba Yaïci, 1 Haanel drive, Ottawa (Ontario) K1A 1M1 Canada, Tel: +1 613 9963734, \\ wahiba.yaici@canada.ca
}

Received: 31.05.2019 Accepted:11.06.2019

\begin{abstract}
This paper's primary objective constitutes addressing accessibility to modern energy as well as examining alternatives for diminishing petroleum derivative independency upon production of electricity for both underserved communities and remote northern populaces that are influenced by the negative effects of climatic changes heavily; an example here is Ontario, Canada's Red Lake, which is Canadian isolated northern populations' part. Accordingly, the execution of this microgrid advances improved well-being care as well as instruction while ensuring the green ecological factor in order to battle conditions of global warming within Ontario's energy sector. Additionally, the electrification is needed to support the isolated communities as well as the nation to accomplish increasingly swift viable and societal goals. This investigation is carried out utilising the Hybrid Optimization Model for Electric Renewables tool referred to as HOMER. Various simulations with different setups were examined. It has been discovered that the microgrid with the utilisation of numerous sustainable power sources blend delivers an optimum result.
\end{abstract}

Keywords Microgrid, hybrid renewable energy system, energy storage system, wind power; hydroelectric power, northern remote community, HOMER.

\section{Introduction}

Achieving accessibility to electricity at a reasonable price range continues to be a challenge for more than 200,000 people living in Canada's as many as 300 remote communities as per a recent Conference Board of Canada report. Their dependence on locally produced electricity implies that power costs can be multiple times higher (as much as 9 times) compared to the Canadian normal. Coming up short on a connection with the primary electricity grid of North America, such communities depend entirely on electricity that is generated locally, which ordinarily originates from costly and polluting diesel-controlled production facilities. Notwithstanding the greater expenses they create, diesel fueled generators likewise impose harmful impacts upon the Earth's environment, releasing high amounts of air pollutant emissions that negatively influence local residents' health. Remote communities of Canada are situated across the nation and vary in size from as few as 10 residences to more than 20,000 occupants' residences. With respect to Canada in its entirety, a disproportionately enormous number of remote communities dominantly contain Aboriginal populaces. In every one of Canada's three territories, all communities can be classified as remote and neither one of the communities has a connection to the main electricity grid of North America.

By not possessing accessibility to the main electricity grid of North America, remote communities cannot achieve benefits from the economies of scale that are received by the grid-connected communities in addition to having a lot higher power costs. To illustrate, in Kugaaruk, Nunavut, the residential electricity rate, which is unsubsidised is more than 
9 times as high $(\$ 1.14 / \mathrm{kWh})$ compared to the Canadian average $(\$ 0.12 / \mathrm{kWh})$. Hence, rates are often financed by provincial governments to guarantee the affordability factor. Notwithstanding the poor economies of scale, the diesel generators controlling majority of the remote communities possess higher operational expenses compared to many of the other power-generation technologies. For diesel fuel, the cost of transportation is high, particularly for communities lacking access to roads. Enormous volumes of diesel being stored over a long period of time likewise serves to drive up expenses as the storerooms are costly where buying and maintenance is concerned. Additionally, since the cost of diesel fuel is firmly connected to crude oil costs, power costs for remote communities often experience fluctuations. In addition to diesel controlled generators' higher operational expenses, there is the concern for the harmful impacts upon the environment. Diesel controlled generators emanate enormous amounts of air contaminants that negatively influences local air quality as well as local residents' health.

Although the remote communities of Canada are found across the nation while having their very own circumstances, there are an assortment of solutions they can exploit for addressing challenges linked to the electricity system. Choices to help lessen dependence on diesel generation constitute utilisation of natural gas and hydro generators, and wind turbines as well as numerous other innovative advancements. Then again, choices that decline electricity utilisation can incorporate the usage of smart meters and improving the efficiency of energy [1]. In north-western Ontario, Canada, 25 remote First Nations communities exist. Such communities are viewed as remote since they do not have a connection to the district power grid and also, due to majority not having access to roads all year round. As referenced in the previous paragraph, electricity administration inside these communes is provided by district diesel generators.

Generally, at present, diesel-fuelled power generation is the most expensive power production asset that is providing Ontario consumers; typically, it costs 3 to 10 times more compared to provincial supply mix's average cost [2]. Subsequently, for building a solid energy supply at moderate cost, increase access sustainably to present-day energy advances as well as services for lower-salary householders and social offices, adopt to a progressive change from customary to advanced energy, guarantee green sustainability and production of unpolluted energy, a hybrid microgrid sustainable power system has turned into an appealing solution as it is viewed as favourable for the generation of clean energy due to not delivering carbon dioxide alongside other ozone depleting substances to the air that contribute to global warming. It should be noted however that as a result of its erratic and most prominent reliance on environmental situations, energy storage systems should be utilised to guarantee that the load is met consistently [3].

As per [4, 5], there are various difficulties that have posed a hindrance to the advancement and full-scale tackling of certain critical energy assets. The strongest hindrances may be a high investment cost upfront of decentralised energy systems in addition to little reasonable funding being obtainable to project engineers, absence of market development and buying capacity at customer stages, the little and scattered environment of power need, especially in remote areas emerging from the small concentration of populace and small salary amounts as well as absence of infrastructures [6]. The fundamental challenges to upgrade energy accessibility is power disconnects occurring at a regular basis, low inclusion of grid power systems driving decentralised renewable alternatives, key resources' availability, such as sustainable power sources and developing acknowledgment of a need to diminish petroleum product reliance given the high oil costs; to further add, there is also the significance of increasing power pass to improvement and the current rise in environment associated as well as contributor funding for low carbon and climate resilient developments becoming available, which makes renewables a priority [7].

The expanding exploitation of the renewable energy sources and the irregularity of the electricity produced by them generate the following issues in the main electrical grid: 1) stability; 2) reliability; and 3) power quality concern $[8,9]$. Storage of energy gives various valuable services as well as cost savings to the power grid. Energy storage on a large-scale basis additionally enables the present power structure to progress fundamentally more productively and that further prominent proficiency implies progressively steady electricity, enhanced in power quality via frequency control, fewer cost and fewer contaminant discharges while giving a continual power supply for both principal infrastructure and amenities [10, 11].

The Hybrid Optimization Model for Electric Renewables (HOMER) software [12-14] was used as a modelling tool, which as of late has been applied for sizing and simulation of micro-grids by numerous scientists in various nations [15-20]. As revealed by a literature review, numerous feasibility and techno-economic studies were embraced in different nations on micro-grid projects, explicitly on stand-alone hybrid energy systems for applications in remote areas or within northern communities [21-42].

In view of building upon and expanding the past authors's study [43], utilisation of sustainable hybrid energy source system with energy storage, which could support or replace existing diesel generator in the remote community of northern Canada was considered. As per our insight, it gives the idea that no feasibility study or some other work form have been performed on such a system for the remote communities of northern Canada and it guarantees our investigation's originality. This paper is expected to examine the technical and economic feasibility, both the integration and optimal sizing of renewables and storage of microgrid for remote electrification within Red Lake, Ontario, Canada. The study is essentially performed utilising the simulation tool referred to as HOMER ${ }^{\circledR}$ Microgrid Software. Monetary examinations concerning present and yearly worth, levelized cost of electricity (COE), investment return, simple payback time and grid expansion have been carried out through various arrangements of generation mix as independent and as a hybrid system. The remaining paper is composed as 
follows: Section 2 gives a full portrayal of the proposed microgrid model as well as the optimisation algorithm, Section 3 provides the primary model information, for example, input information and load profiles and Section 4 presents results of simulation and their discussion while Section 5 gives conclusions.

\section{Methodology}

\subsection{Case Study Approach}

For designing a microgrid of various generation mix power systems utilising HOMER software, input information are needed, for example, hourly load profile, monthly sunbased radiation, wind speed and flow of water for PV system, wind turbine as well as hydroelectric system requirements. The initial cost, substitution and operations and maintenance cost of every part (sustainable power sources, diesel generators, storage systems, such as batteries and hydrogen fuel cells, and converters), diesel fuel price, yearly real interest cost, lifetime of the project etcetera additionally have to be given. Furthermore, solar radiation and wind speed as well as water river flows information for the microgrid that is proposed for the community, were retrieved from online data made available by Environment Canada and other Canadian organisations [44-48]. The capital expense of every equipment was obtained from [49] and changed in accordance with local value via including transportation and different expenses. Taking into consideration the total energy demand or load profile of the clients for the remote region, calculation is performed through multiplying the wattage of the apparatuses consumed and time of equipment consumption as clarified in the paragraph to follow. Computations were performed for estimating the load profile of homes, health buildings, educational institutions and public administrations as well as mills. In this analysis, data for monthly solar radiation, diesel fuel value, PV, battery and converter costs have been utilised as affectability factors. A hybrid renewable energy system's last ideal solution is alluding to the most minimal levelized cost of electricity (COE $\$ / \mathrm{kWh}$ ) as well as least total NPC.

\subsection{Developed Microgrid Model and Optimisation Procedure}

The technique utilised in this study depends on an optimisation method as well as sensitivity analysis that consider assumptions, system design, demand side management (DSM), resource appraisal, and recognisable proof of limitations. As referenced in the last paragraph, the input parameters incorporate the initial cost, replacement and O\&M fee of every module, for example, sustainable power sources, diesel generators, energy storage systems, such as batteries and hydrogen fuel cells, and converters, diesel fuel price, and project lifetime's yearly annual interest rate; it is to be noted that these are only a few factors mentioned. HOMER simulates the dynamic activity of an integrated hybrid renewable energy system. The energy balance computation is played out each hour for a year's every one of the 8760 hours for an arranged configurations list based upon the Net Present Cost (NPC). The former signifies the system'slife cycle cost, which is under concern. Then, the simulation tool assesses all expenditures occurring amid the project lifespan, containing the expenses of initial system, part replacement, maintenance as well as fuel. At that point, the numerical tool emphasises the optimisation procedure for each choice of affectability or sensitivity factors.

In this investigation, the sensitivity factors incorporate solar radiation, PV, battery and converter costs, and diesel fuel cost. The enhanced hybrid sustainable power source arrangement is alluded to the ideal result for a system with the most minimal levelized cost of power and least total NPC. The algorithm, in HOMER gives the most conceivable or ideal system arrangement, which is the result for a system that fulfils the consumer's defined imperatives at the present, least total net expense. The ideal system set-up is an element of various parameters the client has control of, for example, settling on the mix of system components, the component amount or capacity, and the dispatch as well as control methodology that the system should utilise. The optimisation procedure comprises of cycles of a wide range of system configurations considering solutions for the ones infeasible or for those that are deemed as not being able to fulfil the consumer's defined restrictions and the plausible ones. The viable arrangements are positioned dependent on complete NPC as well as the optimal system structure as the one with the most minimal absolute NPC.

The goal of the optimisation approach involves locating the optimal estimation of every decision variable fixed as a goal or is of any significance for the system in examination. A choice variable is characterised as one over which the user has control and for one the HOMER optimisation algorithm can present a few plausible estimates. In HOMER, potential choice factors include the PV array size, wind turbines' quantity, hydro system presence, every generator's size, the quantity of batteries, the size of AC-DC converter for the electrolyzer and hydrogen storage reservoir, the dispatch plan, which is identified with the arrangement of standards controlling the system functionality. It should be mentioned that on account of hydro system, HOMER can take into consideration about just one size of it; then, the judgment is whether the energy system ought to incorporate the hydro system. Optimisation is a valuable approach, which be capable of enable the designer to locate the optimum or ideal system arrangement out of different alternatives. Figure 1 presents the simulation, optimisation and sensitivity procedures in HOMER. Figure 2 demonstrates the developed microgrid model with the optimisation algorithm utilised in this analysis, permitting system function of various sustainable power sources alongside energy storage systems and after that, explore their communications as well as the impacts of certain sensitivity values. 


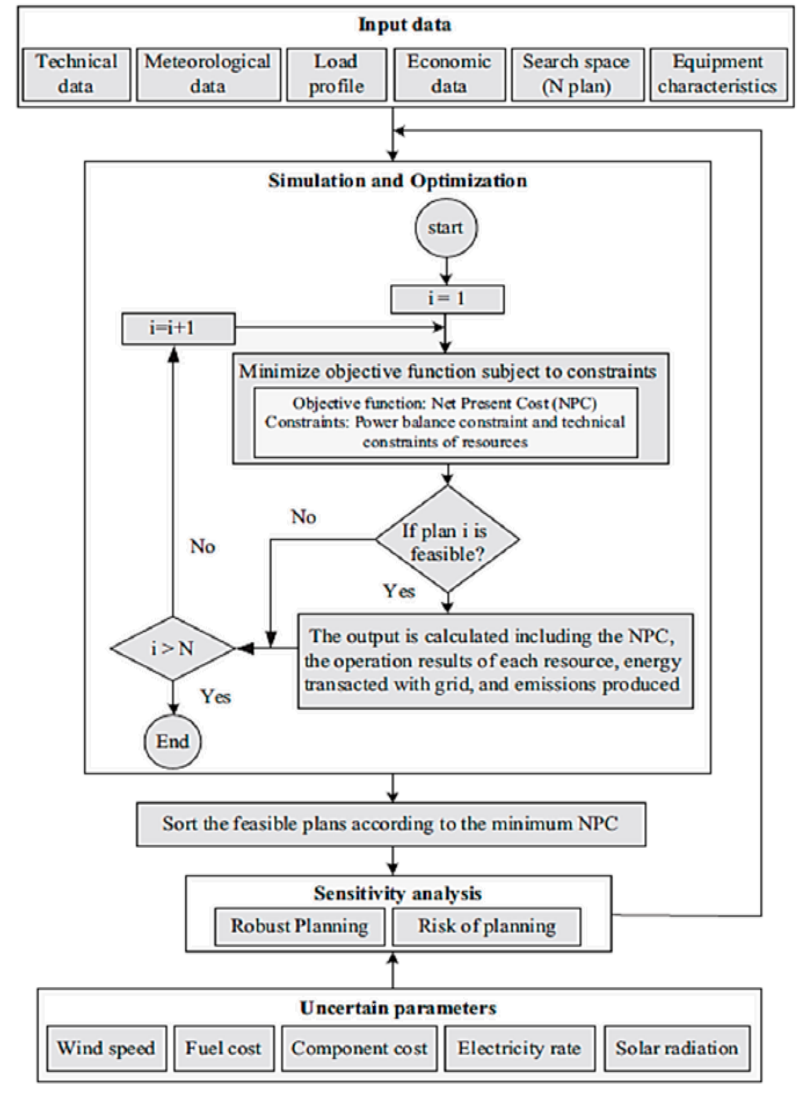

Fig. 1. Simulation, optimisation and sensitivity procedures in HOMER [20].

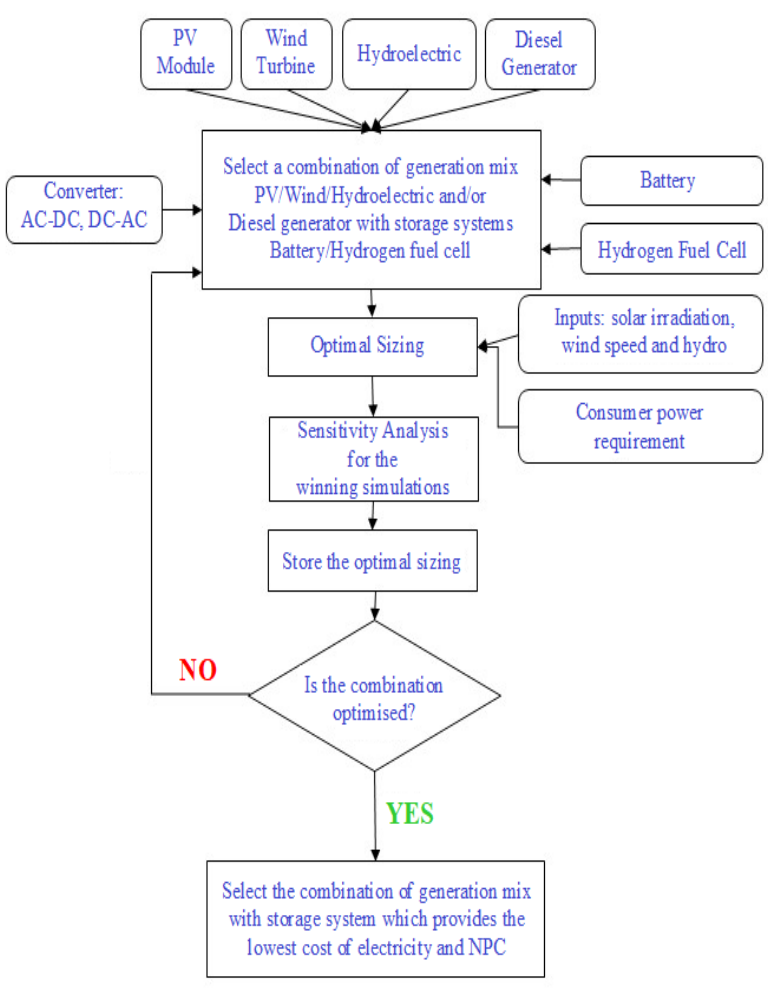

Fig. 2. Developed microgrid model and optimisation procedure for this work.

\section{Data Collection and Load Profiles}

\subsection{Data Collection}

Red Lake is a region with town type in Canada's province of Ontario; it is found 535 kilometres northwest of Thunder Bay and under 100 kilometres from the boundary of Manitoba. The district comprises of six little communities. According to the Canada 2011 Census, it had a populace of 4,670 individuals. It is an reserve inside Unorganized Kenora District. Figure 3 illustrates the area within the northwestern Ontario Red Lake region.

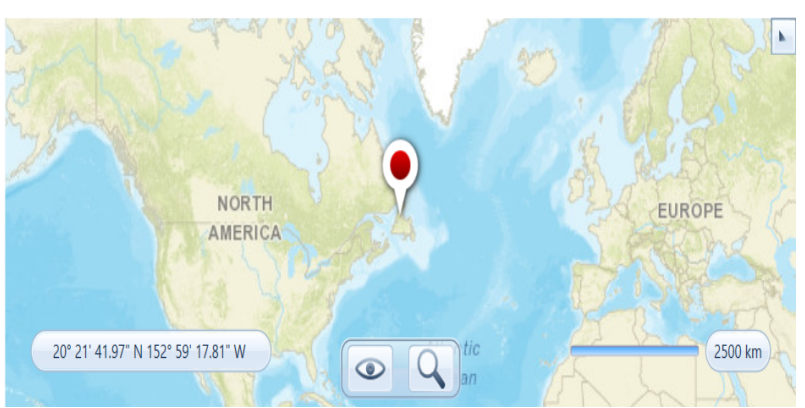

Fig. 3. Location of Red Lake, Ontario, Canada.

Our investigation was restricted both in choice of storage systems and topographical area of the location where the microgrid is intended for the remote electrification. An extensive correlation and evaluation of all storage advancements is fairly aspiring; it is on the grounds that a varied assortment of prospective uses are already available and numerous through altogether diverse specialised prerequisites that might be best met with various technologies.

A few sustainable power sources, such as solar, wind and hydropower, and diesel as well as 'standby alternative' power producing technology arrangements have been considered and the total NPC of every system setup has been determined for 25 years (lifetime of set-up) for the evaluation of the most cost-effective energy choice. In this research piece, for the studied region, the monthly average radiation information has been retrieved from Natural Resources Canada and other centres [46-48] as displayed in Table 1. As indicated by the aforementioned information sets, the district gets yearly average solar irradiation of $3 \mathrm{kWh} / \mathrm{m}^{2} /$ day.

Table 1. Average solar irradiation data for Red Lake, Ontario, Canada

\begin{tabular}{l|cccc}
\hline $\begin{array}{l}\text { Month } \\
\begin{array}{l}\text { Solar Irradiation } \\
\text { (kWh/m²/day) }\end{array}\end{array}$ & 1.1 & 1.9 & 2.9 & 3.9 \\
\hline $\begin{array}{l}\text { Month } \\
\text { Solar Irradiation } \\
\text { (kWh/m²/day) }\end{array}$ & 4.6 & 5.1 & 4.8 & 4.3 \\
\hline $\begin{array}{l}\text { Month } \\
\text { (Solar Irradiation } \\
\text { (kWh/m } / \mathbf{m a y})\end{array}$ & 3.2 & Jun. & Jul. & Aug. \\
\hline
\end{tabular}


Michela Longo et al., Vol.3, No.2, June, 2019

Wind speed data has been retrieved as a 10-year average on monthly basis at an anemometer height of $50 \mathrm{~m}$ over the earth's surface via Environment Canada and other databases [49-51] as displayed in Table 2. As per the information, the yearly average wind speed of this district is $6.1 \mathrm{~m} / \mathrm{s}$, regarded as great wind speed. It is to be noted that the wind speed is commonly a function of the sea level height. For various elevations above sea level, for example of 100, 150 and 300 $\mathrm{m}$, the yearly average wind speed is evaluated to be 6.8, 7.2, and $7.1 \mathrm{~m} / \mathrm{s}$, respectively.

Table 2. Average monthly wind data for Red Lake, Ontario, Canada

\begin{tabular}{lcccc}
\hline Month & Jan. & Feb. & Mar. & Apr. \\
Wind speed (m/s) & 6.7 & 6.7 & 6.8 & 6.3 \\
\hline Month & May & Jun. & Jul. & Aug. \\
Wind speed (m/s) & 5.9 & 5.7 & 5.0 & 4.8 \\
\hline Month & May & Jun. & Jul. & Aug. \\
Wind speed (m/s) & 5.6 & 6.1 & 6.7 & 7.1 \\
\hline
\end{tabular}

The suggested hydropower system is a form of run-offriver type that needs the assurance of accessible head and flow rate at pour points; here the yearly scaled average of $6,15(1 / \mathrm{s})$ is displayed in Table 3. This information has been retrieved via Ref. [52].

Table 3. Average monthly hydro resources for Red Lake, Ontario, Canada

\begin{tabular}{lcccc}
\hline Month & Jan. & Feb. & Mar. & Apr. \\
Stream flow ( 1/s) & 245 & 158 & 286 & 787 \\
\hline Month & May & Jun. & Jul. & Aug. \\
Stream flow ( 1/s) & 457 & 1,704 & 24,402 & 30,666 \\
\hline Month & Sep. & Oct. & Nov. & Dec. \\
Stream flow ( 1/s) & 6,608 & 5,704 & 974 & 734 \\
\hline
\end{tabular}

\subsection{Load Profile}

The utilisation of domestic electricity indicates big fluctuations relying upon atmosphere, culture and supply reliability as well as site. For the most part, rural family units in developing nations have small utilisation with the essential usages constituting lighting, cooking and TV. The investigation and structure of micropower systems can pose a challenge because of the enormous number of design alternatives as well as the vulnerability in main parameters, for example, load size and variation in cost of storage, and sustainable sources' capital expense. Sustainable electricity sources contribute added difficulty due to the power output factor that might be intermittent, seasonal or nondispatchable. HOMER was intended to defeat these difficulties [12, 13]. Microgrid investigation of collective power access in Red Lake needs time series data for the purposes of home load profile. Each day, seasonal and yearly electrical load profiles were created and computed using HOMER. The total energy utilised every day, $E_{\mathrm{T}}$ for a particular load is as follows:

$$
E_{T}=\sum_{i=1}^{m} n P_{i} T_{i}=E_{1}+E_{2}+E_{3}+\cdots \ldots+E_{m}
$$

where, $n$ is the amount of the machine $i$ in use and $P_{i}$ is the appliance $i$ 's power rating and $T_{i}$ constitutes the time of machine $i$ usage.

Table 4 introduces the percentage utilisation and power demand in Red Lake, Ontario, Canada. As per [53], the aforementioned table an average load's results at 3,417.6 $\mathrm{kWh}$ and 6,634.2 $\mathrm{kWh}$ for the Residential and Community, and Industrial and Commercial load profiles, respectively. Additionally, a sum of $241,244.7 \mathrm{kWh} /$ day minus the thermal load that will be incorporated into the simulation as 24,000 $\mathrm{kW} /$ day is also shown.

Henceforth, an evaluation of $30 \mathrm{MW}$ peak load is needed for completely supplying and extending access of power within the region. In Figure 4, the load profile per every day in Red Lake is reported.

Fig. 4. Daily load profile for Red Lake, Ontario, Canada.

From the above-shown graph, the absolute utilisation of power can be obtained, in the wake of comprising the thermal load by the community as a Scaled Annual Average, Average, and Peak, and Load Factor that are 265,245 $\mathrm{KWh} /$ day, $11,052 \mathrm{~kW}$ and $30,000 \mathrm{~kW}$, and .55 , respectively. 
Michela Longo et al., Vol.3, No.2, June, 2019

Table 4. Load profile of Red Lake, Ontario, Canada

\begin{tabular}{|c|c|c|c|}
\hline Category & Sector & $\begin{array}{c}\text { Consumption } \\
(\%)\end{array}$ & Electricity Consumption (kWh) \\
\hline $\begin{array}{l}\text { Residential \& } \\
\text { Community Load }\end{array}$ & $\begin{array}{l}\text { Residential } \\
\text { Public Administration } \\
\text { Transportation } \\
\text { Agriculture }\end{array}$ & $\begin{array}{l}29.5 \\
2.5 \\
0.2 \\
1.8\end{array}$ & $\begin{array}{c}2,965.3 \\
251.3 \\
20.1 \\
180.9\end{array}$ \\
\hline $\begin{array}{l}\text { Industrial \& } \\
\text { Commercial Load }\end{array}$ & $\begin{array}{l}\text { Commercial } \\
\text { Industrial } \\
\text { Other }\end{array}$ & $\begin{array}{c}26.4 \\
38.8 \\
0.8\end{array}$ & $\begin{array}{c}2,653.7 \\
3,900.1 \\
80.4\end{array}$ \\
\hline & Total & 100 & $10,051.9$ \\
\hline
\end{tabular}

\section{Results and Discussion}

A series of numerous designs has been examined and led in Red Lake (Ontario, Canada) with the assistance of the HOMER Pro energy optimisation tool as displayed in Figure 5. The aforementioned is especially concentrating on distributed and sustainable power sources, battery storage system in extending power access to remote zones and amplifies its commitment to handle the widespread power limitation. The utilisation of hydrogen and flywheel as a storage system has additionally been considered; yet, their expense is shockingly unfit when considering a lesser expense for battery as a storage system.

After performing and simulating a series of design configurations, the microgrid system requires $52,082 \mathrm{~kW}$ of $\mathrm{PV}, 122$ of $1.5 \mathrm{MW}$ wind turbines, 4267 string of $24 \mathrm{~V}$ battery stockpiling alongside $10,595 \mathrm{~kW}$ of hydropower systems and 22,015 kW ABB PVS800-1000 kW converters for its optimal functionality. Thus, as revealed in Table 5, an ideal arrangement is presented for attaining electricity access and scaling up this power access to the remote communities constitutes PV-Wind-Hydro-Battery hybrid system that will address the issue with minimum NPC, working cost, COE and substantial Renewable fraction, as provided in Table 5.

Table 5. Optimised results for the microgrid in Red Lake, Ontario, Canada

\begin{tabular}{lcccc}
\hline $\begin{array}{l}\text { Microgrid } \\
\text { Generation } \\
\text { Mix }\end{array}$ & $\begin{array}{c}\text { Total } \\
\text { NPC } \\
\left(\$^{1}\right)\end{array}$ & $\begin{array}{c}\text { Operating } \\
\text { cost } \\
\left(\$ \$^{1} / Y r\right)\end{array}$ & $\begin{array}{c}\text { COE } \\
\left(\$^{1} / \mathrm{K}\right. \\
\mathrm{Wh})\end{array}$ & $\begin{array}{c}\text { Renewable } \\
\text { Fraction \% }\end{array}$ \\
\hline $\begin{array}{l}\text { PV-Wind- } \\
\text { Hydro- } \\
\text { Battery }\end{array}$ & $675 \mathrm{M}$ & $7,386,754$ & 0.60 & 90.61 \\
$\begin{array}{l}\text { PV-Hydro- } \\
\text { Battery }\end{array}$ & $714 \mathrm{M}$ & $8,303,421$ & 0.63 & 90.59 \\
\hline
\end{tabular}

\footnotetext{
${ }^{1}$ Canadian Dollar
}

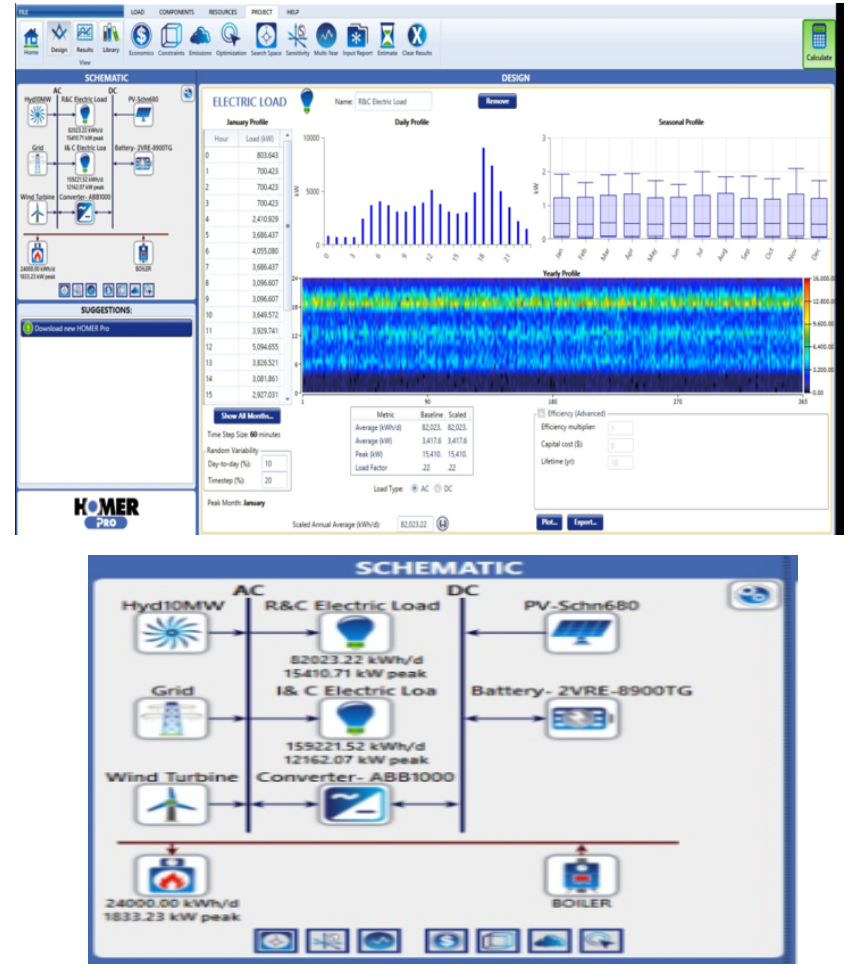

Seasonal Profile

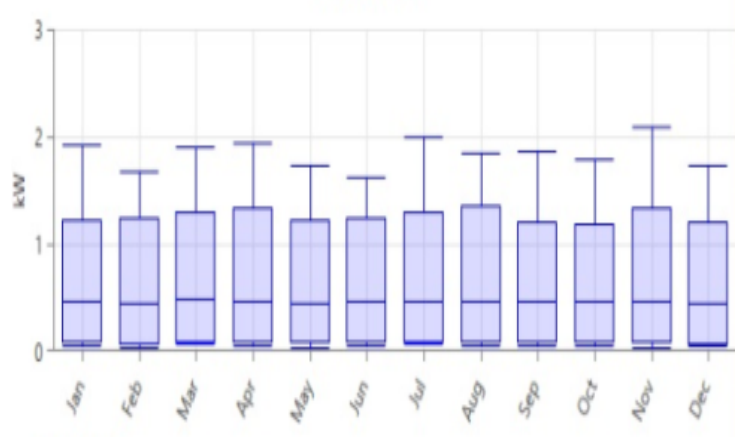

Fig. 5. System arrangement and design of Red Lake, Ontario, Canada. 
The simulation likewise brought about 140,685,691 $\mathrm{kWh} / \mathrm{yr}$ of excess electricity and an unmet load of 3,522,440 $\mathrm{kWh} / \mathrm{yr}$. Also, as displayed in Figure 6, the system comprises of a low working cost, just establishing $1.1 \%$ of the capita cost with no cost involved for fuel. Therefore, the consideration of boiler will produce $2,771,137 \mathrm{~kg} / \mathrm{yr}$ of carbon dioxide emissions and $6871 \mathrm{~kg} / \mathrm{yr}$ of other pollutant emissions. This discloses to us a lot higher production/current capital expense for the microgrid that is proposed. The simulation would additionally help create a microgrid system of power generation containing $65 \% \mathrm{PV}$ array and wind turbine, and $35 \%$ hydro turbines. The Nominal cash flow demonstrates that the system will begin benefitting following 20 years of activity because of the staggering expense of sustainable energy sources for the rural zone (Figure 7). Whenever offered, grid augmentation links the facility to the grid of local utility and is very reliable as well as solid and effective cost-wise where power supply is concerned for the proposed microgrid because for the specific chosen site, the registered breakeven distance constitutes $>500 \mathrm{~km}$.

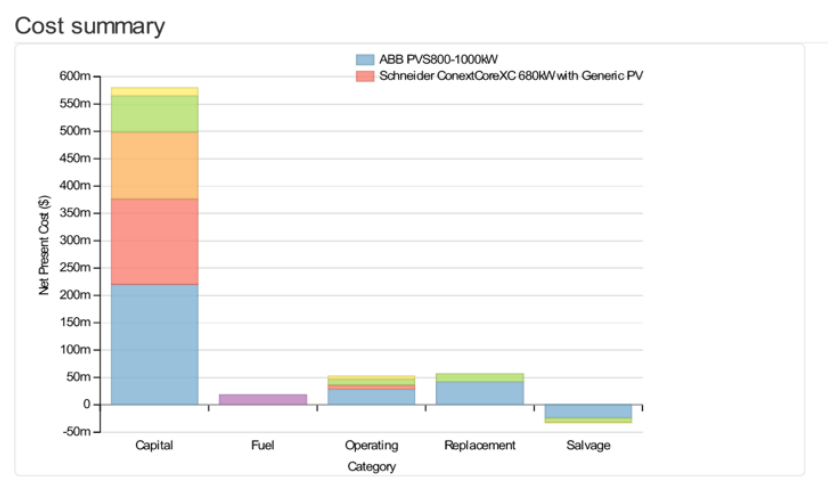

Fig. 6. Cash flow summary for Red Lake, Ontario, Canada.

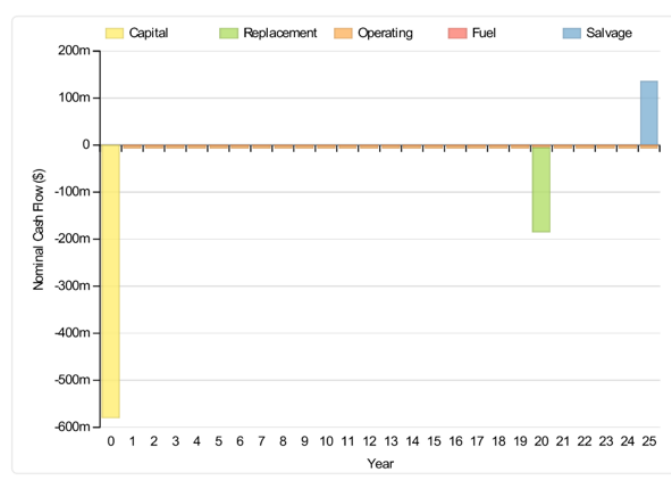

Fig. 7. Nominal cash flow for Red Lake, Ontario, Canada.

It is to be noted however that contrasting the microgrid cost of power from the federal current grid tariff, the microgrid has twice greater expense, which is because of the area of the commune with fewer solar radiation, wind speed and water flow. This may possibly be overturned with the funding from the government and backing from benefactors for low carbon as well as climate resilient development.
Furthermore, with the development of the equipment, it is normal that the expense of sustainable power sources comprising certain storage systems will decrease and this gets our project achievable. Motivated by the principle obstacles in utilising renewable and sustainable power source, the utilisation of storage system tends to perform a noteworthy part in handling the sporadic and unpredictable sustainable renewable power generation. Furthermore, the utilisation of microgrid with various sustainable power sources presents a decrease of starting capital cost while increasing dependability and give community feeling of both safety and get into information. A prominent perception from the above investigation is microgrid's generally high cost. This reality makes the usage of such systems not competitive to the conventional energy systems. Stand-alone systems are generally introduced in regions that are isolated or secluded where the community development is, in fact, or monetarily not attainable. The speculation cost of the introduced independent system is impressively high. The consumption ascends due the surprising expense of civil works, such as wind power or hydro systems and furthermore because of absence of accessibility, for example, the requirement of road construction as well as staggering expenses of materials transportation. Then again, the financial and social effects attained from the establishment of such independent systems are of incredible significance (both power and water supply) in light of the fact that efficient and social advancement is related to the infrastructure. Under such conditions, the high investment cost becomes of minor significance.

\section{Conclusions}

The objective of this work was to deliver access to present day power and to look at alternatives for diminishing fossil fuel reliance on power generation for the remote northern populaces that are heavily influenced by the negative effects of environmental changes and an example of Canada's Red Lake region was discussed in the province of Ontario, where remote northern communities exist. It has been discovered that the utilisation of a mix of various renewable and sustainable power generations is good and favourable than utilising a solitary source, such as WindBattery and additionally PV-Battery systems. The system was simulated with zero MASCC (Maximum Allowed Shortage Capacity) as the remote zone is cold for the most part of the year because of its topographical area and attraction as a vacation spot for tourists. This, in any case, increases the absolute net present cost (NPC) in addition to the cost of electricity (COE). Another simulation with $7 \%$ of MASCC demonstrated a substantial decrease on COE and NPC. Thusly, the execution of on-site microgrids for rural or remote area electrification assumes a significant job for most of the un-electrified communities by meeting the energy use demand services and consequently, be able to diminish the fundamental obstacles in the financial advancements. However, because of the quickening deployment, advancement of technology, continued progress in sustainable power generation technologies' competitiveness and mass production of batteries' manufacturing, the levelized COE as well as the complete NPC are predicted to decrease. 


\section{Acknowledgements}

The authors gratefully acknowledge the support provided by the Department of Energy, Politecnico di Milano and Natural Resources Canada through the Program of Energy Research and Development.

\section{References}

[1] J. Knowles, Power Shift: Electricity for Canada's remote communities. Ottawa: The Conference Board of Canada, 2016.

[2] Ontario Power Authority, Technical Report for the Connection of Remote First Nation Communities in Northwest Ontario For Northwest Ontario First Nation Transmission Planning Committee, Canada, 2012.

[3] C. Barrington-Leigh, M. Ouliaris, The renewable energy landscape in Canada: a spatial analysis, Renewable and Sustainable Energy Reviews 75 (2017) 809-819.

[4] Canada Mortgage and Housing Corporation (2010). Photovoltaic (PV) Systems. Available from: http://www.cmhcschl.gc.ca/en/co/maho/enefcosa/enefcosa $003 . c f m /$ (accessed on 24 May 2019).

[5] Canadian Hydrographic Services (2013). Tides, Currents, and Water Levels. Available from: http://www.chs-shc.gc.ca/twl-mne/index-eng.asp/ (accessed on 24 May 2019).

[6] Canadian Solar Industries Association (2010). Solar Vision 2025: Beyond Market Competitiveness. Technical report, Canada, 2010.

[7] M. Delucchi, M. Jacobson, Providing all global energy with wind, water, and solar power: Part II, Energy Policy 39 (2011) 1170-1190.

[8] J. Nyboer, K. Lutes, A Review of Renewable Energy in Canada, 2009, Technical Report, Burnaby, Canada, 2012.

[9] J. Nyober, Energy Use and Related Data: Canadian Electricity Generation Industry 1990 to 2011, Technical report, Burnaby, Canada, 2012.

[10]D.B. Layzell, S. Jamie, S.M. Wood, Exploring the Potential for Biomass Power in Ontario. Technical Report, Kingston, Canada, 2006.

[11] Hydro Quebec, Comparison of Electricity Prices in Major North American Cities, Technical Report, Canada, 2012.

[12] Software HOMER. Available at: https://www.homerenergy.com/products/pro/index.html (accessed on 24 May 2019).

[13] Getting Started Guide for HOMER Legacy (Version 2.68), January 2011. Available online from: http://www.science.smith.edu/ jcardell/Courses/EGR32 5/Readings/HOMERGettingStartedGuide.pdf (accessed on 24 May 2019).
[14] T. Givler, P. Lilienthal, Using HOMER ${ }$ Software, NREL's Micropower Optimization Model to Explore the Role of Gen-sets in Small Solar Power Systems, Technical Report NREL/TP-710-36774, USA, May 2005.

[15] P. Bajpai, V. Dash, Hybrid renewable energy systems for power generation in stand-alone applications: A review, Renewable and Sustainable Energy Reviews 62 (2012) 2926-2939.

[16] S. Sinha, S.S. Chandel, Review of software tools for hybrid renewable energy systems, Renewable and Sustainable Energy Reviews 32 (2014) 192-205.

[17] S. Upadhyay, M.P. Sharma, A review on configurations, control and sizing methodologies of hybrid energy systems, Renewable and Sustainable Energy Reviews 38 (2014) 47-63.

[18] A.H. Fathima, K. Palanisamy, Optimization in microgrids with hybrid energy systems - a review, Renewable and Sustainable Energy Reviews 45 (2015) 431-46.

[19] K.K. Shivarama, K.K. Sathish, A review on hybrid renewable energy systems. Renewable and Sustainable Energy Reviews 52 (2015) 907-16.

[20] S. Bahramara, M.P. Moghaddam, M.R. Haghifam, Optimal planning of hybrid renewable energy systems using HOMER: A review, Renewable and Sustainable Energy Reviews 62 (2016) 609-620.

[21]B.F. Ronad, Optimal cost analysis of wind-solar hybrid system powered $\mathrm{AC}$ and $\mathrm{DC}$ irrigation pumps using HOMER, Proceedings of the IEEE International Conference on Renewable Energy Research and Applications (ICRERA), Palermo, Italy, pp. 1038-1042, 22-25 November 2015.

[22] A.K. Akella, M.P. Sharma, R.P. Saini, Optimum utilization of renewable energy sources in a remote area, Renewable and Sustainable Energy Reviews 11 (2007) 894-908.

[23] J. Kenfack, F.P. Neirac, T.T. Tatietse, D. Mayer, M.D. Fogue, A. Lejeune, Micro hydro-PV-hybrid system: sizing a small hydro-PV-hybrid system for rural electrification in developing countries, technical note, Renewable Energy 34 (2009) 2259-2263.

[24] M.J. Khan, M.T. Iqbal, Pre-feasibility study of standalone hybrid energy systems for applications in Newfoundland, Renewable Energy 30 (2005) 835-854.

[25] D. Saheb-Koussa, M. Koussa, M. Haddadi, M. Belhamel, Hybrid options analysis for power systems for rural electrification in Algeria, Energy Procedia 6 (2011) 750-758.

[26] S.M. Shaahid, M.A. Elhadidy, Technical and economic assessment of grid-independent hybrid photovoltaicdiesel-battery power systems for commercial loads in desert environments. Renewable and Sustainable Energy Reviews 11 (2007) 1794-810. 
[27] S.B. Silva, M.A.G. de Oliveira, M.M. Severino, Economic evaluation and optimization of a photovoltaic-fuel cell-batteries hybrid system for use in the Brazilian Amazon, Energy Policy 38 (2010) 671323.

[28] T. Ma, H. Yang, L. Lu, A feasibility study of a standalone hybrid solar-wind-battery system for a remote island, Applied Energy 121 (2014) 149-58.

[29] K. Nikhil, M. K. Mishra, S. Kotra, Power management based on the operating conditions of grid, microgrid and hybrid storage, Proceedings of the IEEE International Conference on Renewable Energy Research and Applications (ICRERA), Palermo, Italy, pp. 1437-1441, 22-25 November 2015.

[30] M. Yesilbudak, I. Colak, Main Barriers and solution proposals for communication networks and information security in smart grids, Proceedings of the IEEE International Conference on Smart Grid (icSmartGrid), Nagasaki, Japan, pp. 58-63, 4-6 December 2018.

[31] K.E. Okedu, M. Al-Hashmi, Assessment of the cost of various renewable energy systems to provide power for a small community: Case of Bukha, Oman, International Journal of Smart Grid, Vol.2, No.3, 2018.

[32] T. T. Sepulveda, L. Martinez, Optimization of a hybrid energy system for an isolated community in Brazil, International Journal of Renewable Energy Research, vol. 6, no. 4 (2016) 1476-1481.

[33] Y. Allahvirdizadeh, M. Mohamadian, and $\mathrm{M}$. Haghifam, Study of energy control strategies for a standalone $\mathrm{PV} / \mathrm{FC} / \mathrm{UC}$ Microgrid in a remote area, International Journal of Renewable Energy Research, vol. 7, no. 3 (2017) 1495-1508.

[34] M. M. G. Lawan, J. Raharijaona, M.B. Camara, B. Dakyo, Power control for decentralized energy production system based on the renewable energies using battery to compensate the wind/load/PV power fluctuations, Proceedings of the IEEE 6th International Conference on Renewable Energy Research and Applications ICRERA, San Diego, CA, USA, pp. $1132-$ 1138, 5-8 December 2017.

[35] S. Ruiz Alvarez, A. Márquez Ruiz, and J. Espinosa Oviedo, Optimal design of a diesel-PV-wind system with batteries and hydro pumped storage in a Colombian community, Proceedings of the IEEE 6th International Conference on Renewable Energy Research and Applications ICRERA, San Diego, CA, USA, pp. 234239, 5-8 December 2017.

[36]D. Icaza, F. Córdova, System of electrical generation by wind and solar sources in the archaeological surroundings of the Hill Curiquinga of QuingeoEcuador, Proceedings of the IEEE International Conference on Smart Grid (icSmartGrid), Nagasaki, Japan, pp. 164-170, 4-6 December 2018.

[37] P.R. Bhattarai, S. Thompson, Optimizing an off-grid electrical system in Brochet, Manitoba, Canada.
Renewable and Sustainable Energy Reviews 53 (2016) 709-19.

[38] D. Chade, T. Miklis, D. Dvorak, Feasibility study of wind-to-hydrogen system for Arctic remote locations Grimsey island case study, Renewable Energy 76 (2015) 204-211.

[39] S. Sarker, Feasibility analysis of a renewable hybrid energy system with producer gas generator fulfilling remote household electricity demand in Southern Norway, Renewable Energy 87 (2016) 772-781.

[40] M. Arriaga, C.A. Cañizares, M. Kazerani, Renewable energy alternatives for remote communities in Northern Ontario, Canada, IEEE Transactions on Sustainable Energy, 2012.

[41] S. Ruiz-Álvarez, J. Espinosa, Multi-Objective Optimal Sizing Design of a Diesel-PV-Wind-Battery Hybrid Power System in Colombia, International Journal of Smart Grid ijSmartGrid, Vol. 2, No. 1, March 2018.

[42] M.S.H. Lipu, M.G. Hafiz, M. S. Ullah, A. Hossain, F.Y. Munia, Design Optimization and Sensitivity Analysis of Hybrid Renewable Energy Systems: A case of Saint Martin Island in Bangladesh, International Journal of Renewable Energy Research, Vol.7, No.2, 2017.

[43] M. Brenna, M. Longo, W. Yaici, T.D. Abegaz, Simulation and Optimization of Integration of Hybrid Renewable Energy Sources and Storages for Remote Communities Electrification, Proceedings of the IEEE PES Innovative Smart Grid Technologies Conference Europe (ISGT-Europe), 26-29 September 2017, Torino, Italy.

[44] J. Majorowicz, S.E.S. Grasby, R.W. Kinner Estimation of Shallow Geothermal Energy Resource in Canada: Heat Gain and Heat Sink, Natural Resources Research 18 (2009) 95-108.

[45] National Climate Data and Information Archive of Environment and Climate Change Canada. Available from: http://climate.weather.gc.ca/ (accessed on 24 May 2019).

[46] Solar Resource. Available from: http://www.nrcan.gc.ca/energy/renewableelectricity/solar-photovoltaic/14390 (accessed on 24 May 2019).

[47] Surface Meteorology and Solar Energy. Available from: https://eosweb.larc.nasa.gov/sse/

[48] IRENA, Battery Storage for Renewables: Market Status And Technology Outlook, Abu Dhabi, UAE: International Renewable Energy Agency (IRENA), 2015.

[49] Atmospheric Science Data Center (ASDC), NASA Langley Research Center, https://eosweb.larc.nasa.gov/ (accessed on 24 May 2019).

[50] Environment Canada, Homogenized Wind Speed Data Access Station Information. Available from: https://www.ec.gc.ca/dccha- 
$\underline{\text { ahccd/default.asp?lang=en } \& n=71 C B 3873-1} \quad$ (accessed on 24 May 2019).

[51] Ontario Ministry of Natural Resources, Ontario Wind Resource Atlas [online map]. Peterborough, ON: The Ontario Ministry of Natural Resources, Canada, 2007.

[52] Environment Canada, Government of Canada, Water Level and Flow, https://wateroffice.ec.gc.ca/; https://www.canada.ca/en/environment-climate- change/services/water-overview.html (accessed on 24 May 2019).

[53] Statistics Canada, Manufacturing and Energy Division, Report on Energy Supply and Demand in Canada, Published by authority of the Minister responsible for Statistics Canada , Minister of Industry, Canada, 2012. Available from: https://www150.statcan.gc.ca/n1/pub/57-003-x/57-003x2014002-eng.pdf (accessed on 24 May 2019) 